\title{
Investigation of Stiffening and Curvature Effects on the Residual Strength of Composite Stiffened Panels with Large Transverse Notches
}

\author{
Patrick Enjuto ${ }^{1}$, Thomas H. Walker ${ }^{2}$ and Mark Lobo ${ }^{3}$ \\ NSE Composites, Seattle, WA \\ Eric Cregger ${ }^{4}$ \\ Boeing Research \& Technology, Seattle, WA \\ and \\ Dr. Steven Wanthal ${ }^{5}$ \\ Boeing Research \& Technology, Charleston, SC
}

\begin{abstract}
Design of robust aircraft structure requires consideration of the load-carrying capability with large damage. Large notches, typically introduced as machined cracks (aka "notches") severing a single skin bay and a central stiffening member, are often used to conservatively address the wide range of possible large damage scenarios. The objective of the current effort was to develop more generalized and rapid analysis methods addressing large-notch residual strength of stiffened panels to support preliminary design activities.
\end{abstract}

\section{Nomenclature}

$a \quad=$ half crack length

$A \quad=$ severed stiffener configuration factor coefficient

$A_{\text {beam }}=$ beam area

$A_{\text {stiffener }}=$ stiffener area

$b \quad=$ stiffener spacing

$B=$ severed stiffener configuration factor coefficient

$C=$ first intact stiffener configuration factor coefficient

$D \quad=$ first intact stiffener configuration factor coefficient

$E \quad=$ first intact stiffener configuration factor coefficient

$E_{x} \quad=$ Young's modulus in the x-direction

$E_{y} \quad=$ Young's modulus in the y-direction

$E A \quad=$ product of Young's modulus and area

$F \quad=$ first intact stiffener configuration factor coefficient

$G \quad=$ first intact stiffener configuration factor coefficient

$\mathrm{H}=$ first intact stiffener configuration factor coefficient

$l_{A D} \quad=$ noodle height

$r=$ polar coordinate

$R=$ curved panel radius

$R_{s} \quad=$ stiffening ratio

$t_{f l g} \quad=$ flange thickness

$t_{s k} \quad=$ skin thickness

${ }^{1}$ Senior Stress Engineer, NSE Composites.

${ }^{2}$ Principal Engineer, NSE Composites, AIAA Member.

${ }^{3}$ Senior Stress Engineer, NSE Composites.

${ }^{4}$ Senior Technical Fellow, Boeing Research \& Technology, AIAA Associate Fellow.

${ }^{5}$ Technical Fellow, Boeing Research \& Technology, AIAA Associate Fellow. 


$\begin{array}{ll}U R & =\text { rotation } \\ U & =\text { displacement } \\ w_{f l g} & =\text { flange width } \\ x & =\text { Cartesian coordinate } \\ y & =\text { Cartesian coordinate } \\ Y & =\text { configuration factor } \\ Y_{\text {sig }} & =\text { stress based configuration factor } \\ z & =\text { Cartesian coordinate } \\ \theta & =\text { polar coordinate } \\ \sigma_{c r, c f g} & =\text { critical configured stress } \\ \sigma_{c r, u n c f g} & =\text { critical unconfigured stress }\end{array}$

\section{Introduction}

$\mathrm{P}$ REDICTIVE methods addressing the large-notch capability of metallic structure generally involve factoring the fracture capability of a flat, unstiffened panel using factors that address the configuration variables of the final structure (e.g., curvature, stiffening, etc.). These factors have been determined using a combination of numerical methods and experimental evidence.

Residual strength predictions of composite large-notch configurations are more challenging due to the complexity of the damage mechanisms and resulting trajectories, as well as the additional layup and stackingsequence variables. As a result, progressive damage finite element (FE) analyses are often used for these predictions. Specifically, Boeing has successfully used laminate-level cohesive-zone models (CZM) with prescribed self-similar growth to address translaminar damage growth in the skin and stiffeners, together with cohesive or VCCT approaches to address skin/stiffener disbonding. This methodology has involved explicit modeling of the entire stiffener cross-sectional geometry.

The complexity and computational intensity of these strategies preclude their direct usage in preliminary design studies, where thousands of configurations may be evaluated. Instead, this methodology is used to analyze a range of configurations over the design space of interest, and response surface equations are developed to predict the residual strength. These response surfaces have been specific to a stiffener cross-sectional shape (i.e., hats, blades, I's, bulbs, etc.), loading (i.e., longitudinal tension, longitudinal compression), and a set of design-variable limits. Parametric FE models are often developed and used in support of the response surface development to provide efficient, error-free model generation across a range of design geometries.

The response surfaces can be developed using standard response surface methods (Reference 1) that use linear combinations of polynomial terms addressing the main effects (i.e., design variables) and their interactions. One byproduct of this approach is that rapid changes in the predicted residual strength can occur in the response surface beyond the limits of the underlying data, severely restricting their application to new design spaces. The resulting response-surface equations, while providing a good representation of the response over the design space of interest, provide little insight into the physical responses and their interactions.

The objective of the current effort was to develop more generalized and rapid analysis methods addressing largenotch residual strength of stiffened panels to support preliminary design activities. More specifically, the effort was limited to addressing the effects of curvature, central severed stiffener, and the first adjacent intact stiffener on the residual strength of panels with bonded or cocured stiffeners, subjected to uniaxial compression loading and exhibiting self-similar damage growth. By developing an improved understanding of key trends over broad ranges of the design variables, appropriate functional forms can be selected for use in the response surfaces, thereby ensuring applicability of the surfaces over a wide range of design variables typical of preliminary design.

\section{Finite Element Methodology}

\section{A. Modeling Approach}

An FE modeling approach using ABAQUS ${ }^{\circledR}$ (Reference 2) was developed for predicting the effects of key variables on large-notch residual strength of stiffened panels. Quarter-symmetric models were used, as shown in Figure 1. This approach includes explicit modeling of the skin and stiffener flanges, but idealizes the stiffener webs and caps as beam elements, as shown in Figure 2. Cohesive response is included to simulate translaminar fracture of the skin and flange, and disbonding of the flange from the skin. 


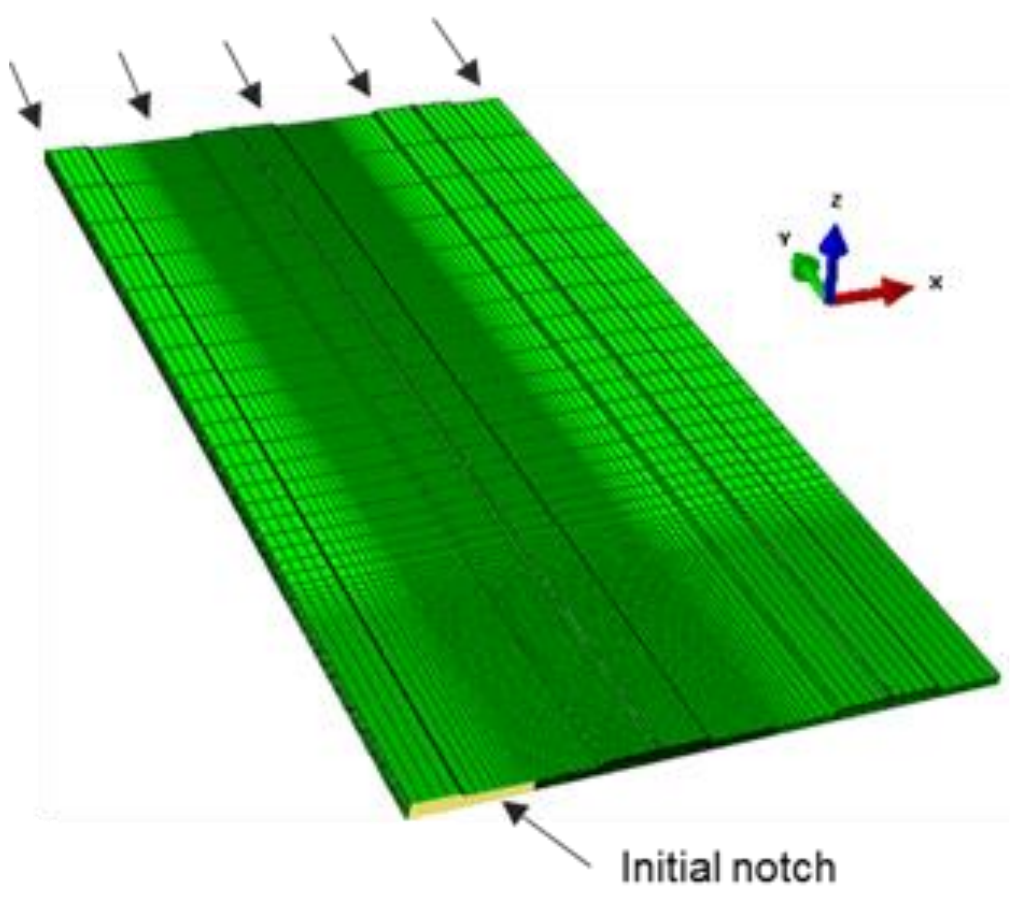

Figure 1. Quarter-Symmetric FE Model.

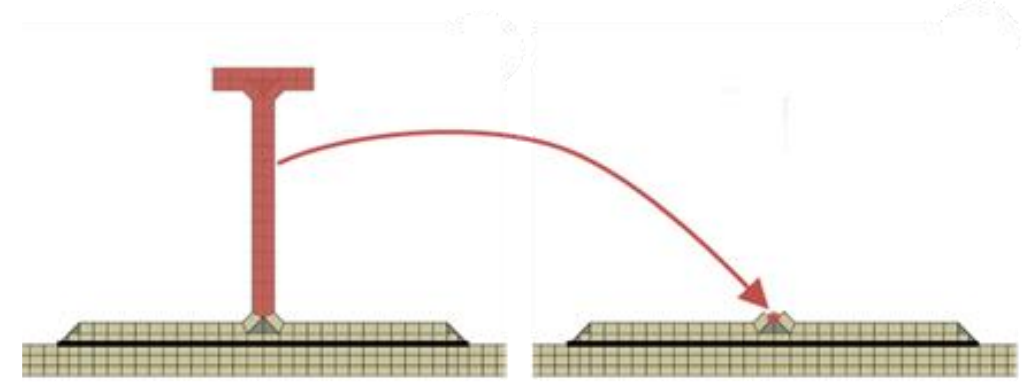

\section{Figure 2. Detail of Modeling Approach Showing Beam Element Representing the Web and Cap of the Stiffener.}

The skin was modeled using 8-noded continuum shell elements (SC8R) with three elements through the thickness. The stringer caps and webs were modeled using linear Timoshenko beam elements (B31), and skinflanges were each modeled with two equal-thickness SC8R elements through-the-thickness. For modeling convenience, the chamfers on the attached stringer flanges were all modeled as a $45^{\circ}$ taper angle with zero thickness at the tip. Six-noded solid wedge elements (C3D6) were used in these areas. The corner radii of the stringer channels were idealized as straight, $45^{\circ}$ segments. The noodle was simulated using C3D6 elements.

Damage growth from the initial through-thickness skin notch was modeled using cohesive elements. One bay of damage growth in the skin was accommodated, as well as growth in the 1st adjacent stringer. In these areas, a single element or an overlaid pair of cohesive elements were used to connect each skin and stringer element to the symmetry boundary. Eight-noded versions (COH3D8) were generally used, except at the flange chamfer and the noodle, where 6-noded versions (COH3D6) were used. The faces of each cohesive element were coincident in the unloaded state.

Cohesive elements were also used to simulate the progressive skin/stringer disbonding that can accompany skin crack growth under the intact stringers. The area of possible disbonding extended from the crack plane to the closest rib location for the 1st adjacent stringer. An initial disbond is used for the first flange, and is taken as the first row of elements ( 0.25 inches along the panel length) across the full width of the first stringer flange. Conceptually, this 
initial disbond provides some relief to the skin crack from the constraining stringer, such as would occur due to delaminations in the skin accompanying the damage growth. All other skin/stringer attachments were rigid.

\section{B. Boundary Conditions}

\section{Flat Panel Model}

The flat model boundary conditions and loading are illustrated in Figure 3. The ribs were simulated using a combination of boundary conditions and constraint equations. Specifically, the rib closest to the crack was idealized by constraining the out-of-plane (UZ) and transverse (UX) displacements for all skin OML nodes to be zero. The rib closest to the load introduction was idealized by constraining the transverse displacements and using constraint equations requiring identical out-of-plane displacements of all skin OML nodes.

Symmetry conditions were used along the longitudinal panel centerline. Along the transverse panel centerline (i.e., the crack plane), a combination of conditions were used. The region with the initial crack was unconstrained. In the region beyond the initial crack, cohesive elements were used to connect the panel to the boundary. A symmetry condition was applied to the cohesive elements' faces that were not attached to the skin or stringer elements. Specifically, the axial displacements (UY) of these cohesive element faces were restricted to zero, while the transverse and out-of-plane displacements (UX and UZ, respectively) were equated to those of the corresponding skin or stringer nodes using constraint equations.

The model was loaded using uniform displacement of all skin and stringer nodes along the loading end. Transverse and out-of-plane displacements were constrained on that end to simulate the effect of potting.

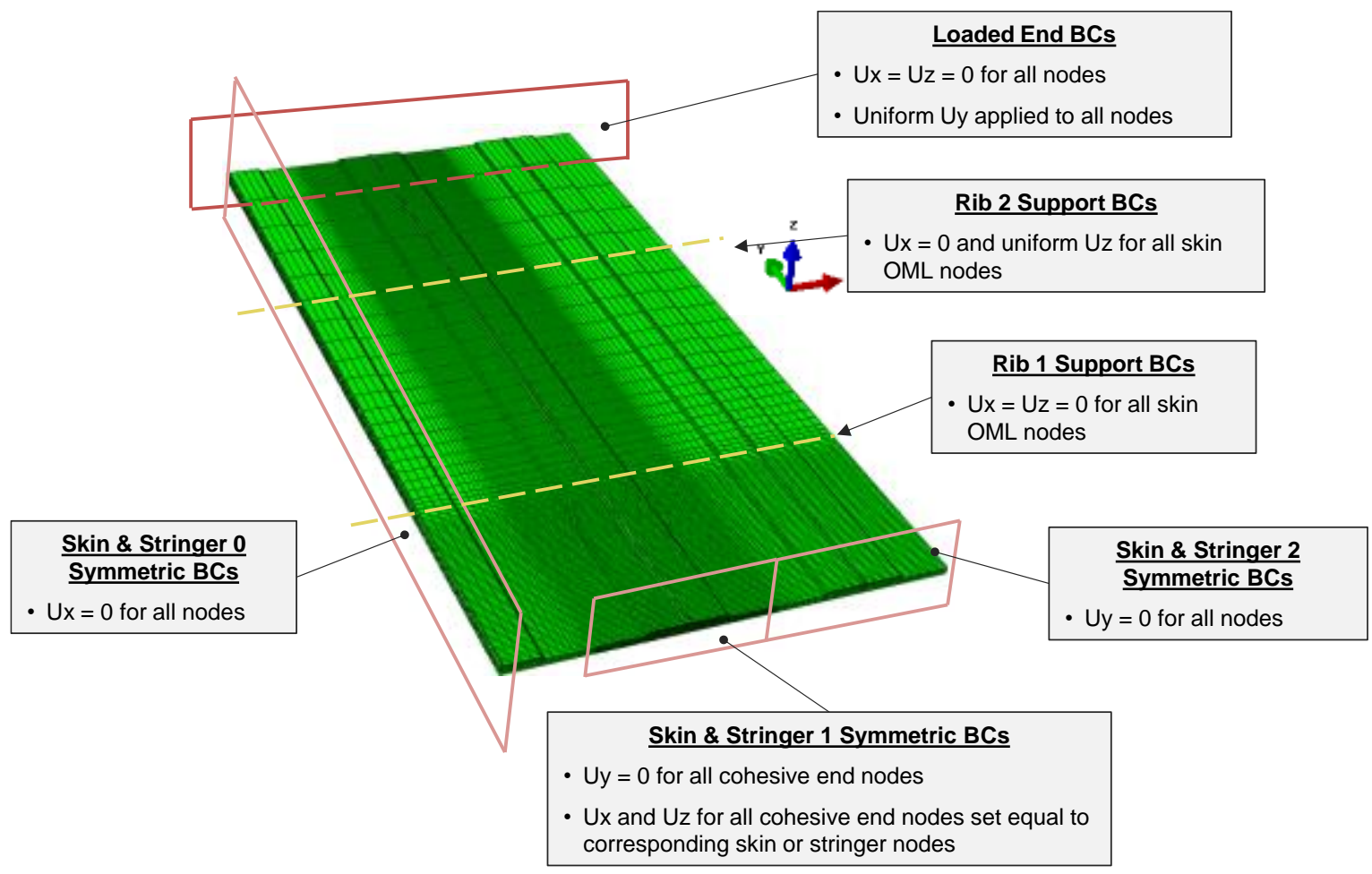

Figure 3. Flat Model Boundary Conditions.

The beam boundary conditions and loading are illustrated in Figure 4. Symmetry conditions were used along the longitudinal panel centerline. Along the transverse panel centerline (i.e., the crack plane), a symmetry condition was applied. Specifically, the axial displacements (UY) and rotations URy and URz were restricted to zero, while the transverse and out-of-plane displacements (UX and UZ, respectively) were equated to those of the corresponding cohesive nodes. 


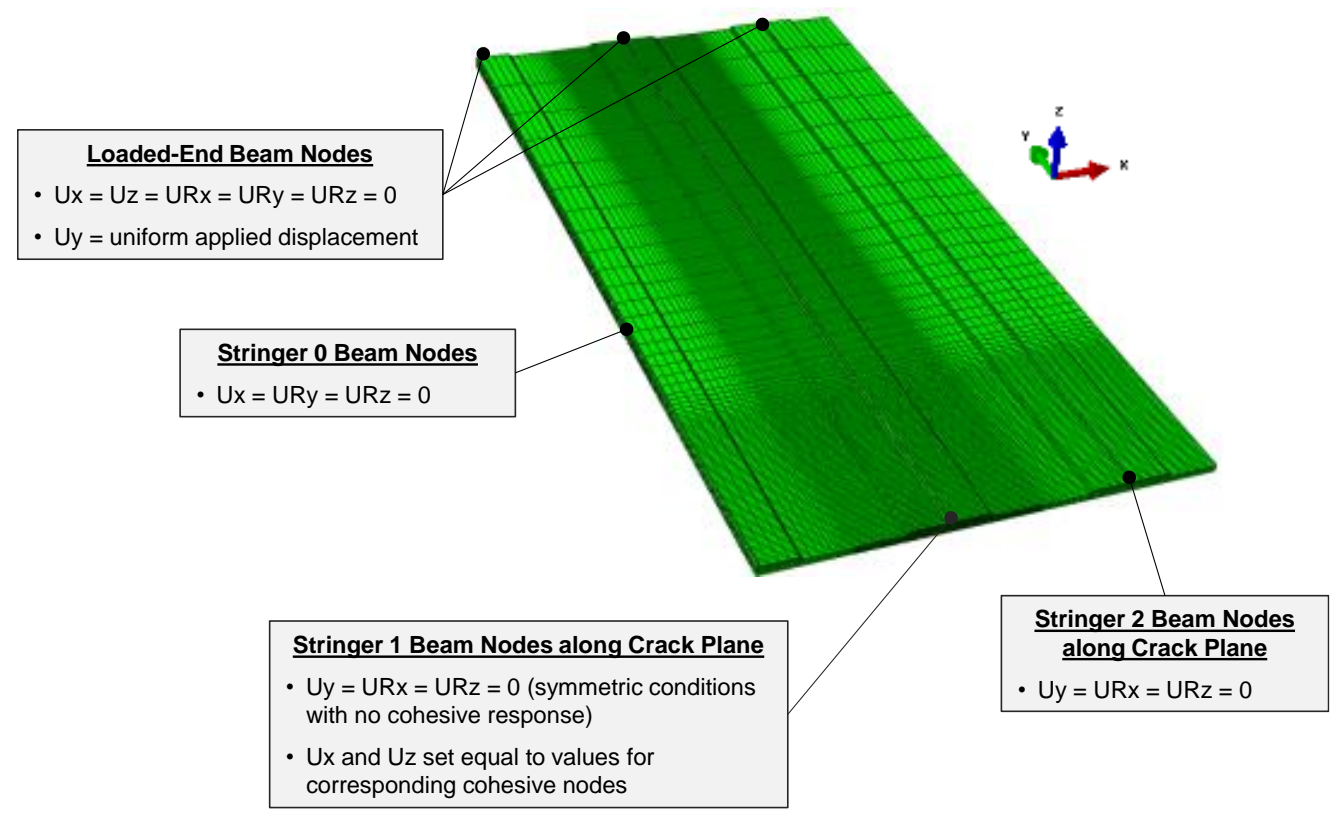

\section{Figure 4. Beam Boundary Conditions.}

Certain compatibility conditions are enforced between the beam nodes and their adjacent nodes, see Figure 5. Axial (y-direction) displacement compatibility is enforced to distribute the beam's axial load across the full width of the stringer web. To achieve this, the beam node (node A) displacement is related to the adjacent nodes (nodes B and C) as per Eq. (1). Furthermore, in order to link the beam element rotation with the adjacent nodes, the rotation compatibility about the stringer longitudinal axis (y-direction) is enforced as per Eq. (2).

$$
\begin{gathered}
U_{Y, A}-\frac{1}{2} U_{Y, B}-\frac{1}{2} U_{Y, C}=0 \\
U R_{Y, A}-\frac{1}{l_{A D}} U_{X, A}+\frac{1}{l_{A D}} U_{X, D}=0 \\
\text { where } l_{A D}=\text { noodle height }
\end{gathered}
$$

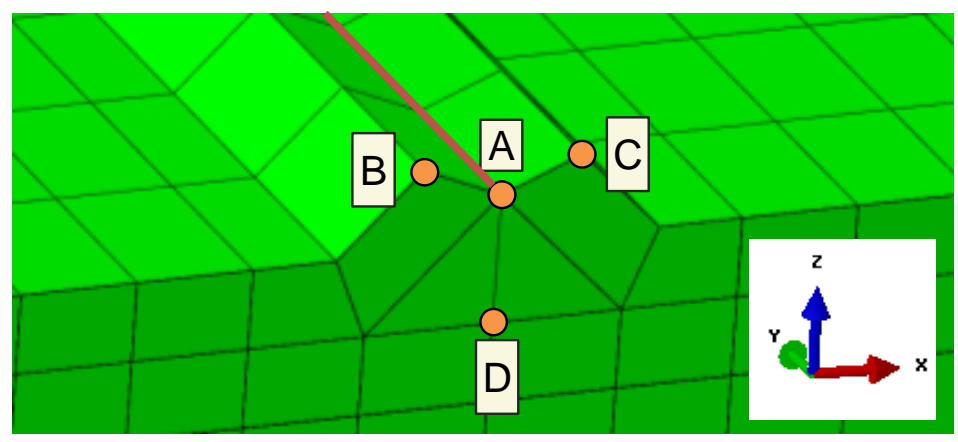

Figure 5. Beam Element Integration. 


\section{Curved Panel Model}

The curved model boundary conditions and loading are illustrated in Figure 6. The curved model boundary conditions and loading are analogous to those of the flat panel model with the exception of the periodic symmetry boundary condition applied to the longitudinal panel end to account for a cylindrical shell configuration.

Additionally, the effect of modifying the compatibility conditions in Eqs. (1)-(2) to account for curvature was found to be insignificant and its implementation deemed unnecessary.

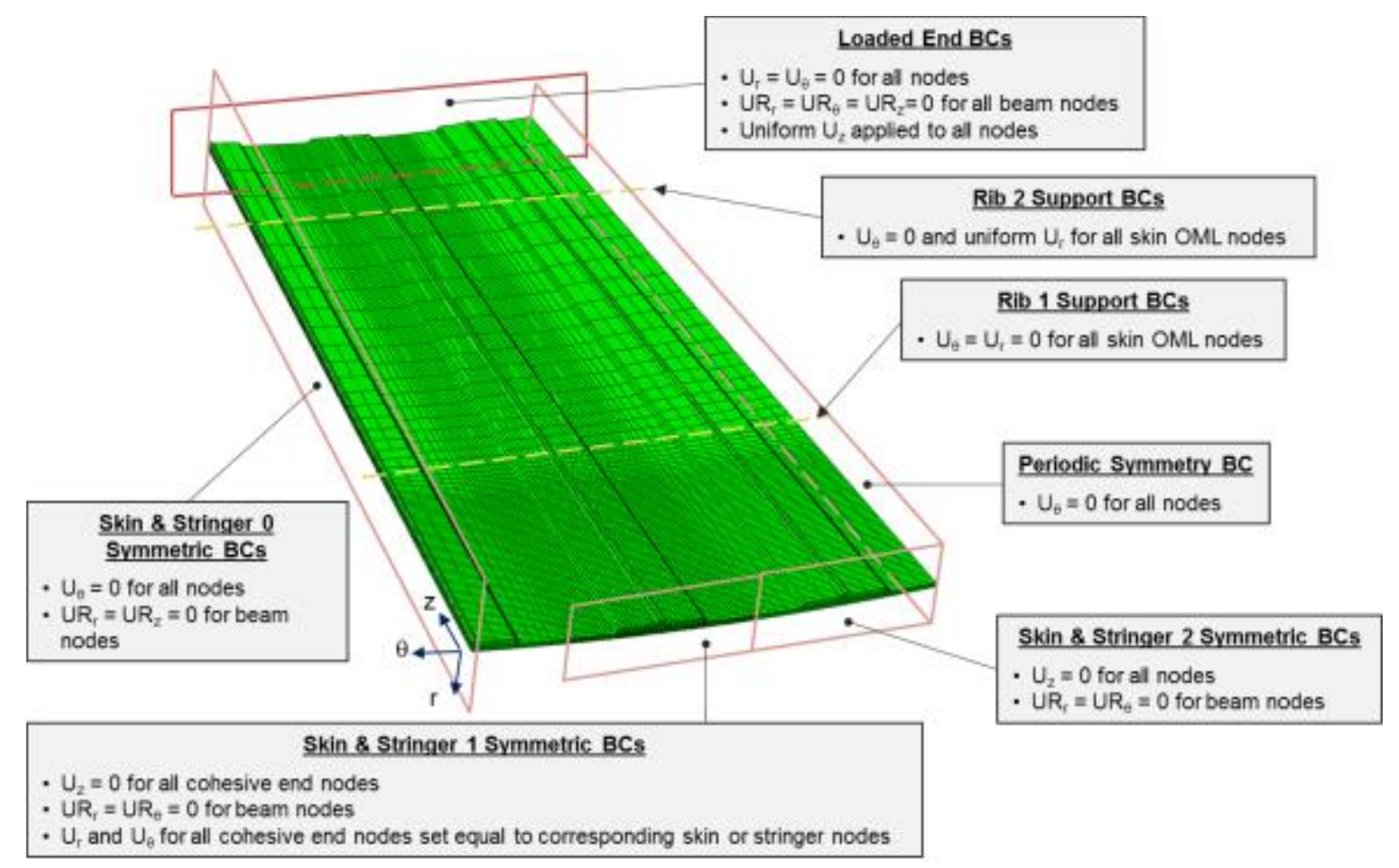

Figure 6. Curved Model Boundary Conditions.

\section{Cohesive Modeling of Through-Thickness Damage}

Cohesive elements were used to model the through-thickness damage growth in the skin and stringer. Cohesive laws were determined for each specific laminate by adjusting the law in a series of FE analyses of flat, unstiffened, notched panels such that the predicted strengths matched the "target" residual strength response over a range of notch sizes. The mesh sizes and analysis parameter settings in these unconfigured FE models were as close as possible to those in the associated stiffened-panel model. Out-of-plane deformations were constrained as needed to avoid transverse buckling along the notch edge prior to reaching the peak load.

A bi-linear softening law was used to incorporate the "crush zone" effect, which addresses the load-carrying capability of the laminates after initial compressive failure. The key attribute of this type of response is a relatively low load-carrying capability over a very large deflection range. A "tail" was added onto the base cohesive law, as shown in Figure 7, to simulate this response. 


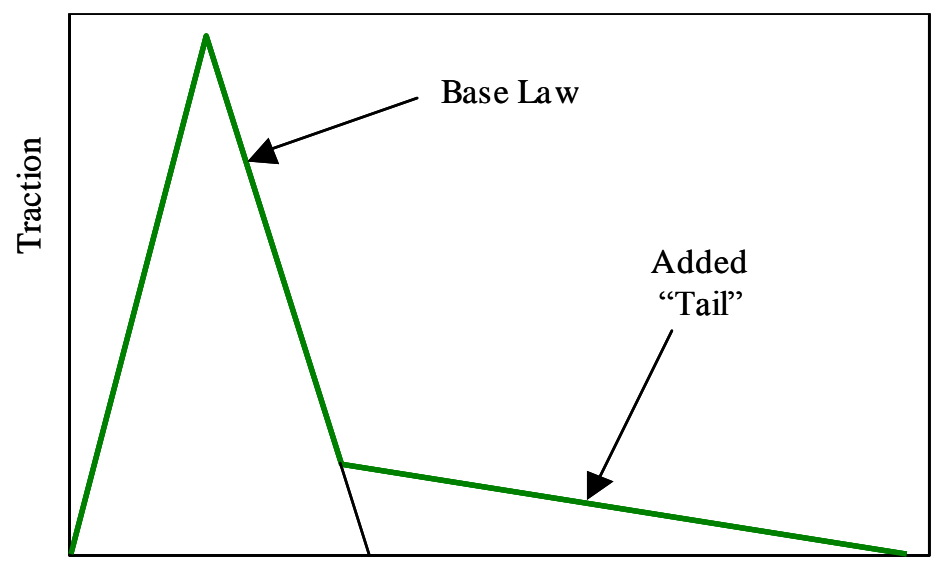

Separation

\section{Figure 7. Bilinear Cohesive Law.}

The bilinear softening was implemented by superimposing two linear-softening cohesive elements. The cohesive law for each of the elements is easily determined from the desired bilinear law, as illustrated in Figure 8.

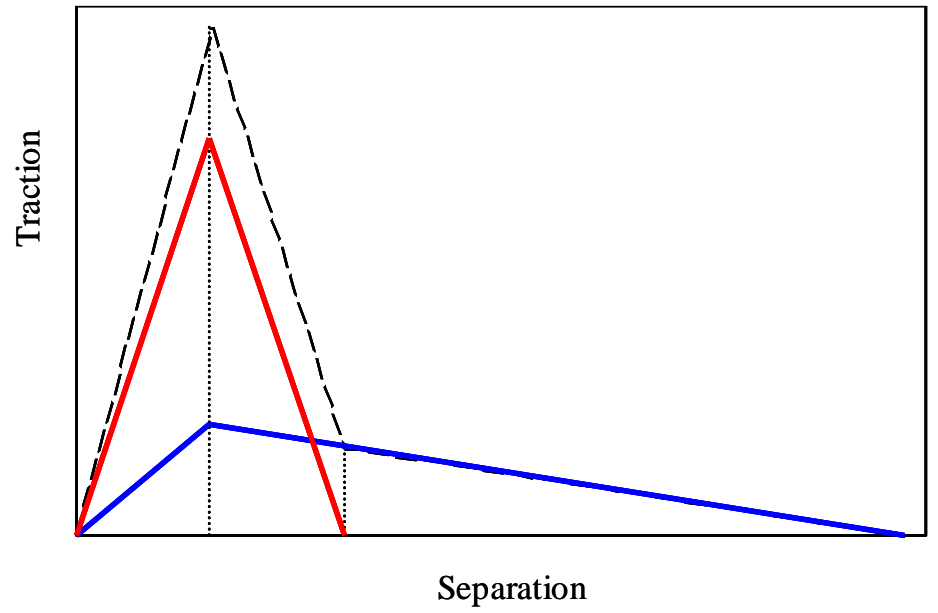

Figure 8. Obtaining Bilinear Cohesive Response via Superposition of Linear Cohesive Laws.

\section{Cohesive Modeling of Skin/Stringer Disbonding}

Cohesive elements were used to simulate the progressive skin/stringer disbonding that can accompany skin crack growth under the intact stringers. The cohesive laws for each of the three fracture modes were defined using semiinfinite stiffnesses, and generic fracture toughness values and initiation stresses. Mode II and III used identical laws.

\section{Closed-Form Trends and Approaches}

An extensive literature review associated with metallic and composite structures was performed to identify anticipated trends and analytical approaches that may form the basis of a non-FE analysis prediction methodology.

The effect of the panel configuration on its large-notch residual strength has often been assumed to be independent of the skin fracture response. With this assumption, the panel strength is then determined by applying a configuration (Y-) factor to the strength of a flat, unstiffened panel of the skin material/layup with a notch of the same length. In many cases, the configuration factors for each effect (e.g., central stiffener, adjacent stiffener) are characterized independently, and are multiplicatively combined when applied, see Eq. (3). 


$$
\sigma_{c r, c f g}=\frac{\sigma_{c r, u n c f g}}{Y_{s i g}}=\frac{\sigma_{c r, u n c f g}}{Y_{1} \cdot Y_{2} \cdot Y_{3} \cdots}
$$

The traditional compounding approach using configuration (Y-) factors was adopted to account for the effect of geometry on the residual strength, since it tends to separate the effects of different variables on the residual strength. This approach facilitates the understanding of the effects of the different design variables by the analyst when approaching the residual strength problem.

Anticipated trends were identified for the effects of curvature, the central severed stiffener, and the first intact stiffener on the residual strength of panels with bonded or cocured stiffeners, subjected to longitudinal compression loading and exhibiting self-similar damage growth.

\section{A. Curvature Effects}

The detrimental effect of curvature on the stress intensity factor of unstiffened panels with long transverse notches subjected to longitudinal tension loading was presented by Sanders ${ }^{3}$, and Forman, Hickman and Shivakumar ${ }^{4}$. The presence of the notch results in out-of-plane displacements (see Figure 9) due to the bendingextension coupling characteristic of shells, which in turn result in an increase of the stress intensity. This effect is relieved as the magnitude of the longitudinal load is increased due to the stiffening effect of the membrane stresses produced by the out-of-plane response.

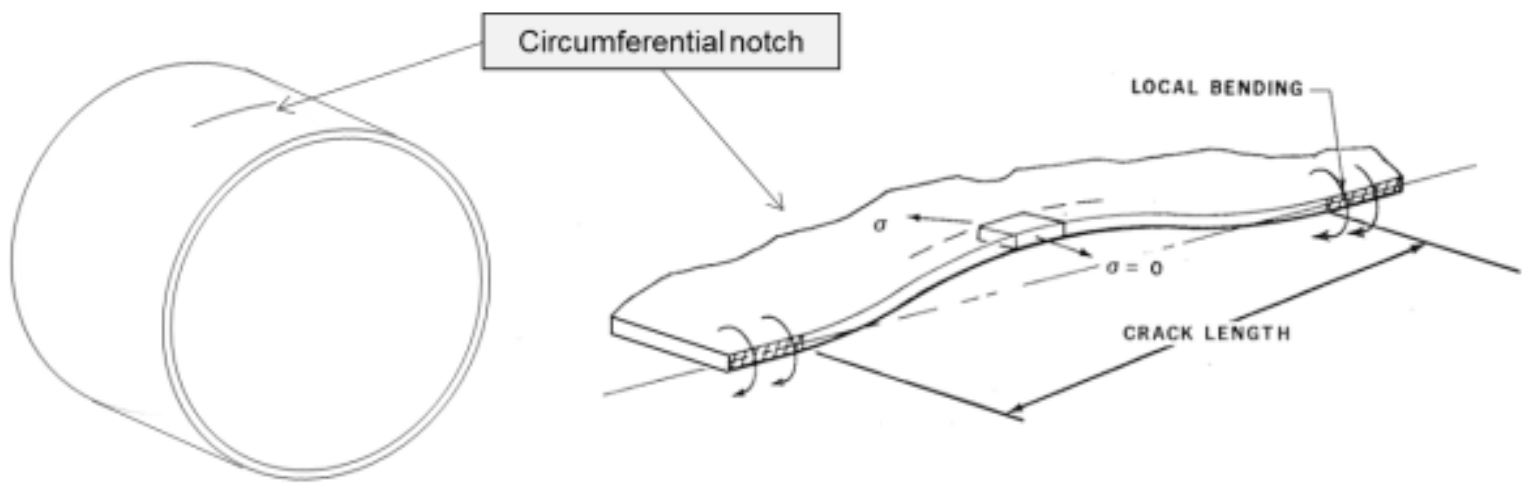

\section{Figure 9. Out-Of-Plane Response of a Curved Shell with a Circumferential Notch under Longitudinal Tension Load (adopted from Swift ${ }^{5}$ ).}

On the other hand, no studies were found on the effect of curvature on the residual strength of stiffened panels with transverse notches under longitudinal loading. It was expected that the presence of the stiffeners would significantly reduce the out-of-plane response characteristic of unstiffened shells. Therefore, instead of adopting functional forms associated with the effect of curvature on unstiffened panels, it was decided to evaluate the existence of detrimental effects due to panel curvature utilizing direct comparis on of flat and curved stiffened panels FE results.

\section{B. Central Severed Stiffener Effects}

A severed stiffener, perpendicular to the plane of the crack and centered at the middle of the crack, reduces the residual strength by transferring additional load into the sheet (i.e., skin), thus increasing the stress intensity.

Sanders ${ }^{6}$ considered the problem of a severed stiffener continuously attached to an infinite sheet subjected to uniaxial tensile stress, with the crack being normal to, and located symmetrically about, the stiffener. Three assumptions are made in Sanders ${ }^{\prime 6}$ analysis:

- The sheet is assumed inextensional in the direction parallel to the crack.

- The crack is treated as a straight line segment and it is assumed that the magnitude of the stress singularity is a measure of the stress concentration due to a thin crack with a small, but nonzero, radius of curvature.

- The stiffener is taken to be a single-line stiffener of cross sectional area $\mathrm{A}_{\text {stiffener }}$ with zero in-plane bending stiffness, and lying in the plane of the plate. 
Based on Sanders' ${ }^{6}$ results (see Table 1 and Figure 10), a linear dependency of the configuration (Y-) factor on the stiffening ratio $\left(\mathrm{R}_{\mathrm{s}}\right)$ was adopted, as shown in Eq. 4 (where $\mathrm{R}_{\mathrm{s}}=\mathrm{EA}_{\text {stiffener }} / \mathrm{EA}_{\text {skin bay }}$, and $\mathrm{A}$ and $\mathrm{B}$ are constants). It should be noted that it is desirable that $\mathrm{B}=1.0$, to guarantee no influence in the absence of the severed stiffener (i.e., when $\mathrm{R}_{\mathrm{s}}=0$ ).

$$
Y_{\text {severed-stiffener }}=A \cdot R_{s}+B
$$

\begin{tabular}{|r|r||r|r|}
\hline \multicolumn{1}{|l|}{$\mathrm{R}_{\mathrm{S}}$} & \multicolumn{1}{l|}{$\mathrm{C}^{*}$} & \multicolumn{1}{l|}{$\mathrm{R}_{\mathrm{S}}$} & \multicolumn{1}{l|}{$\mathrm{C}^{*}$} \\
\hline 0.01 & 1.005 & 0.59 & 1.265 \\
\hline 0.02 & 1.010 & 0.63 & 1.280 \\
\hline 0.03 & 1.017 & 0.67 & 1.297 \\
\hline 0.05 & 1.025 & 0.71 & 1.317 \\
\hline 0.07 & 1.033 & 0.77 & 1.339 \\
\hline 0.10 & 1.049 & 0.83 & 1.365 \\
\hline 0.11 & 1.054 & 0.91 & 1.394 \\
\hline 0.13 & 1.061 & 1.00 & 1.430 \\
\hline 0.14 & 1.069 & 1.11 & 1.472 \\
\hline 0.17 & 1.080 & 1.25 & 1.524 \\
\hline 0.20 & 1.096 & 1.43 & 1.590 \\
\hline 0.25 & 1.119 & 1.67 & 1.676 \\
\hline 0.33 & 1.156 & 2.00 & 1.791 \\
\hline 0.50 & 1.228 & 2.50 & 1.960 \\
\hline 0.53 & 1.239 & 3.33 & 2.230 \\
\hline 0.56 & 1.251 & 5.00 & 2.730 \\
\hline
\end{tabular}

Table 1. Sanders ${ }^{3}$ computed stress concentration factor with a broken stringer $\left(C^{*}\right)$. 


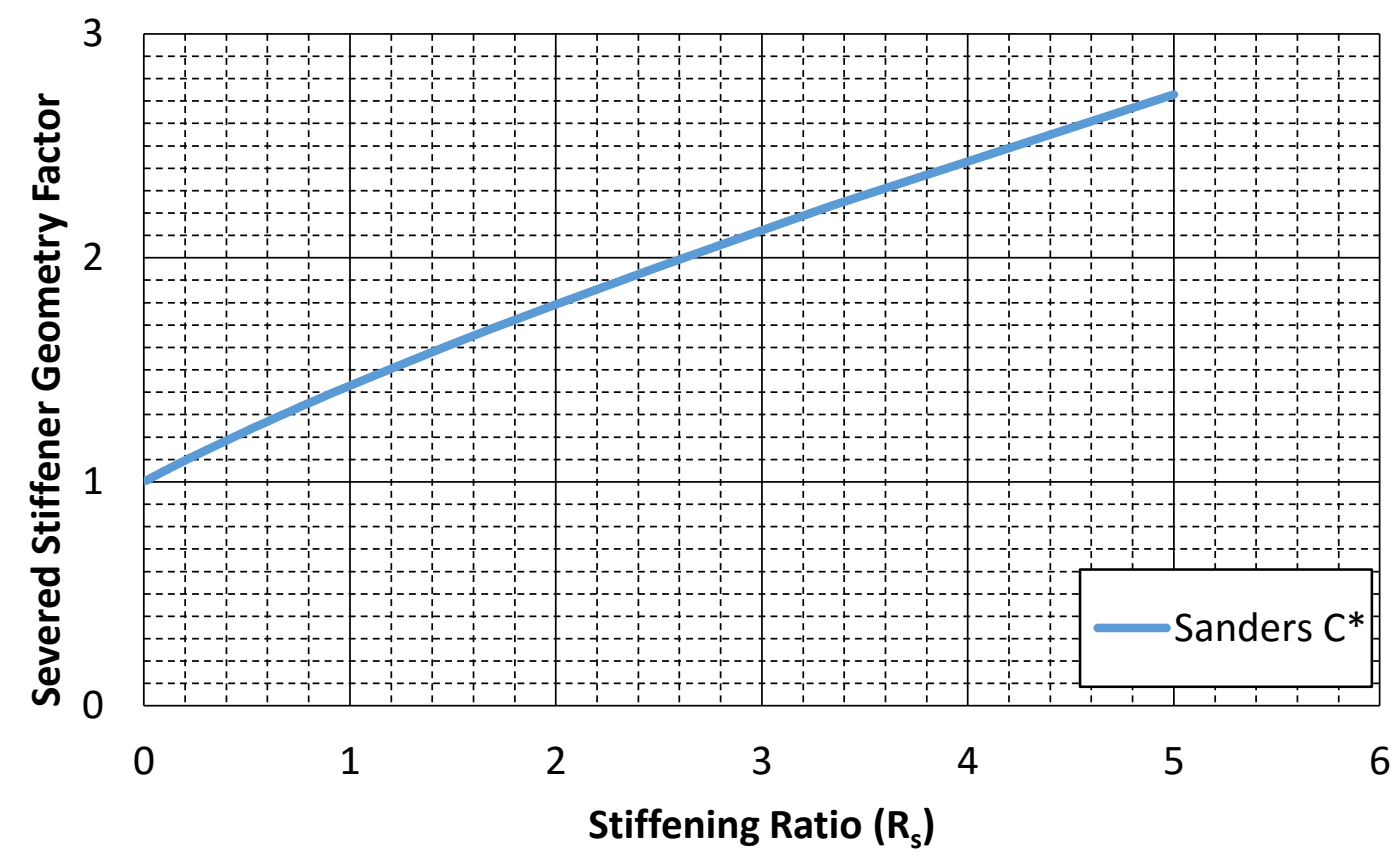

Figure 10. Sanders ${ }^{6}$ computed stress concentration factor with a broken stringer ( $\left.C^{*}\right)$.

\section{First Intact Stiffener Effects}

An intact stiffener, perpendicular to the plane of the crack and located adjacent to the severed stiffener (i.e., the first intact stiffener), results in an increase in the residual strength by reducing the load carried by the sheet, thus relieving the stress intensity at the crack front.

Greif and Sanders ${ }^{7}$ considered the problem of an asymmetric crack approaching an intact stiffener that is continuously attached to an infinite sheet subjected to uniaxial tensile stress, with the crack being normal to the stiffener. Three assumptions were made in Greif and Sanders ${ }^{7}$ analysis:

- The sheet is assumed to be under a state of plane-stress.

- The sheet is assumed to have zero stresses at infinity.

- The stiffener is taken to be a single-line stiffener of cross sectional area $\mathrm{A}_{\text {stiffener }}$ with zero in-plane bending stiffness, and lying in the plane of the plate.

$\mathrm{Poe}^{8}$ produced design graphs that presented the effect of riveted stiffeners (not continuously attached stiffeners) on the residual strength of a stiffened panel with the same assumptions as Greif and Sanders ${ }^{7}$. Subsequently, Nicholls, Jefferson and Martin ${ }^{9}$ showed that Poe's ${ }^{8}$ design graphs for a rivet-pitch (p) to stiffener-spacing (b) ratio $(\mathrm{p} / \mathrm{b})$ of $1 / 12$ were in close agreement with the results obtained by Greif and Sanders ${ }^{7}$, and determined that a 1/12 ratio was appropriate for the analysis of integral structures.

Based on Poe's ${ }^{8}$ results for $\mathrm{p} / \mathrm{b}=1 / 12$ (see Figure 11), a power equation form was adopted for the configuration (Y-) factor, see Eq. 5 (where a is the half crack length, $b$ is the stiffener spacing, $\mathrm{R}_{\mathrm{s}}$ is the stiffening ratio, and $\mathrm{E}, \mathrm{F}$, $\mathrm{G}$, and $\mathrm{H}$ are constants). It should be noted that both $\mathrm{F}$ and $\mathrm{H}$ must be negative in order that $\mathrm{Y}=1$ when $\mathrm{R}_{\mathrm{s}}=0$. 


$$
\begin{aligned}
& Y_{\text {first-stiffener }}=C \cdot\left[2 \cdot\left(1-\frac{a}{b}\right)\right]^{D} \quad \text { where, } \\
& C=\frac{1}{E \cdot\left[\frac{1}{R_{s}}+1\right]^{P}+1} \\
& D=G \cdot\left[\frac{1}{R_{s}}+1\right]^{H}
\end{aligned}
$$

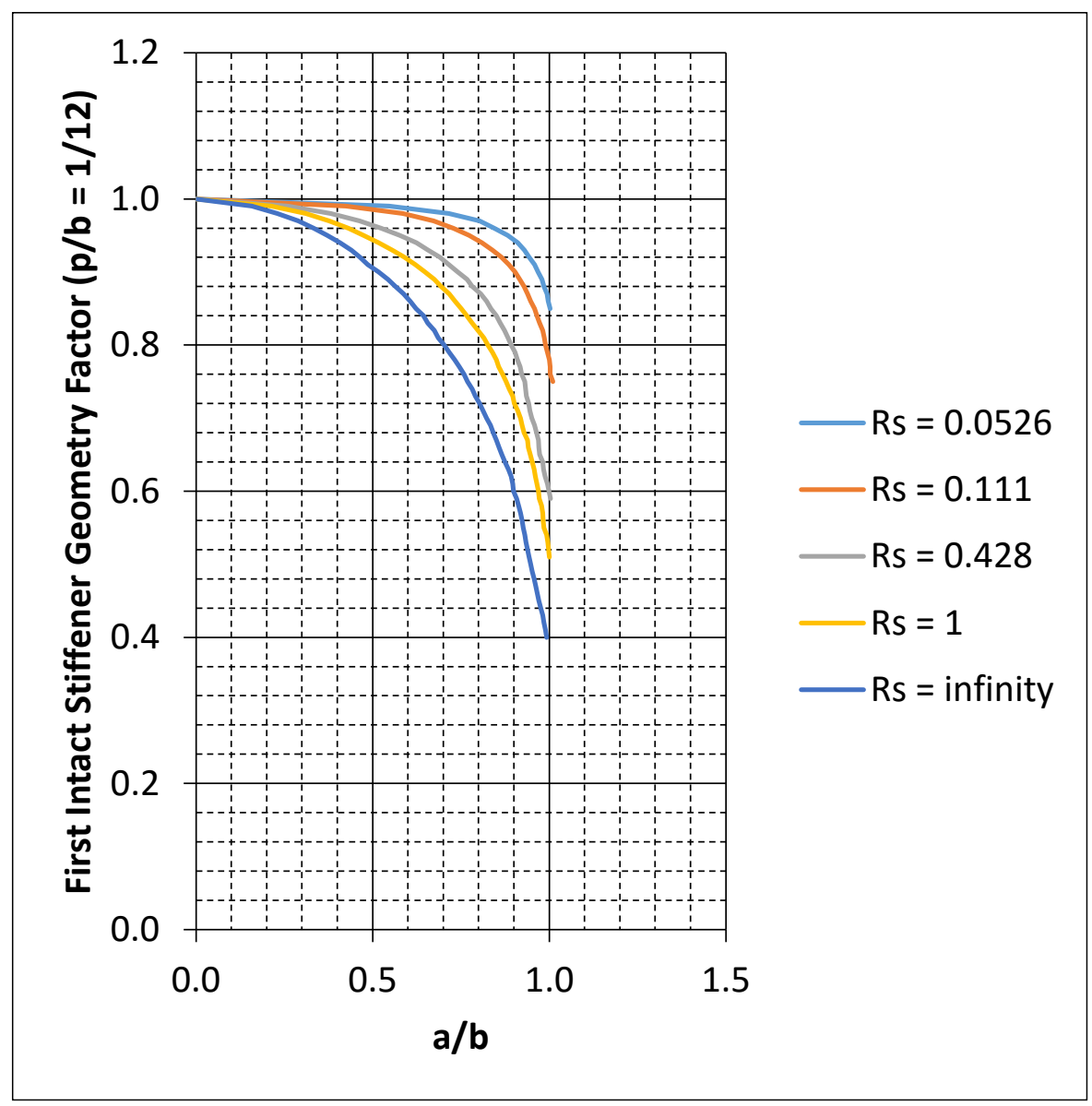

Figure 11. Poe's ${ }^{8}$ first intact stiffener geometry factor.

\section{Results}

In order to evaluate the effect of curvature and to calibrate the functional forms identified in Section III a series of geometrical configurations were analyzed using using the FE methodology discussed in Section II. Table 2 and Figure 12 provide the key variables associated with the 16 configurations analyzed. In the analyses, representative carbon-epoxy composite laminate material properties were used for all panels (i.e., $\mathrm{E}_{\mathrm{x}, \mathrm{skin}}=7.7 \mathrm{msi}, \mathrm{E}_{\mathrm{y}, \mathrm{skin}}=6.9 \mathrm{msi}$, $\mathrm{E}_{\mathrm{x}, \text { stiffener }}=13.0 \mathrm{msi}, \mathrm{E}_{\mathrm{y}, \text { stiffener }}=4.5 \mathrm{msi}, \sigma_{\mathrm{cr} \text {,uncfg,skin }}=18.8 \mathrm{ksi}$ ), and all stiffeners within a single panel were assumed to be identical. Note that $\mathrm{R}_{\mathrm{s}}$ is the stiffening ratio, defined as $\mathrm{EA}_{\text {stiffener }} / \mathrm{EA}_{\text {skin bay. }}$. 


\begin{tabular}{|c|c|c|c|c|c|c|}
\hline Panel ID & $\begin{array}{c}\mathrm{t}_{\mathrm{flg}} \\
\text { (in) }\end{array}$ & $\begin{array}{l}t_{\text {skin }} \\
\text { (in) }\end{array}$ & $\begin{array}{c}b \\
\text { (in) }\end{array}$ & $\begin{array}{l}W_{\text {flg }} \\
\text { (in) }\end{array}$ & $\begin{array}{c}A_{\text {beam }} \\
\left(\mathrm{in}^{2}\right)\end{array}$ & $\mathrm{R}_{\mathrm{s}}$ \\
\hline 101 & \multirow{8}{*}{0.2} & \multirow{4}{*}{0.2} & \multirow{2}{*}{7} & \multirow{2}{*}{3.5} & 0.66 & 1.63 \\
\hline 102 & & & & & 1.32 & 2.43 \\
\hline 103 & & & \multirow{2}{*}{12} & \multirow{2}{*}{6.0} & 1.16 & 1.66 \\
\hline 104 & & & & & 2.32 & 2.47 \\
\hline 105 & & \multirow{4}{*}{0.6} & \multirow{2}{*}{7} & \multirow{2}{*}{3.5} & 0.66 & 0.54 \\
\hline 106 & & & & & 1.32 & 0.81 \\
\hline 107 & & & \multirow{2}{*}{12} & \multirow{2}{*}{6.0} & 1.16 & 0.55 \\
\hline 108 & & & & & 2.32 & 0.82 \\
\hline 109 & \multirow{8}{*}{0.4} & \multirow{4}{*}{0.2} & \multirow{2}{*}{7} & \multirow{2}{*}{3.5} & 1.24 & 3.04 \\
\hline 110 & & & & & 2.48 & 4.54 \\
\hline 111 & & & \multirow{2}{*}{12} & \multirow{2}{*}{6.0} & 2.24 & 3.18 \\
\hline 112 & & & & & 4.48 & 4.76 \\
\hline 113 & & \multirow{4}{*}{0.6} & \multirow{2}{*}{7} & \multirow{2}{*}{3.5} & 1.24 & 1.01 \\
\hline 114 & & & & & 2.48 & 1.51 \\
\hline 115 & & & \multirow{2}{*}{12} & \multirow{2}{*}{6.0} & 2.24 & 1.06 \\
\hline 116 & & & & & 4.48 & 1.59 \\
\hline
\end{tabular}

Table 2. FE analysis configuration definition.

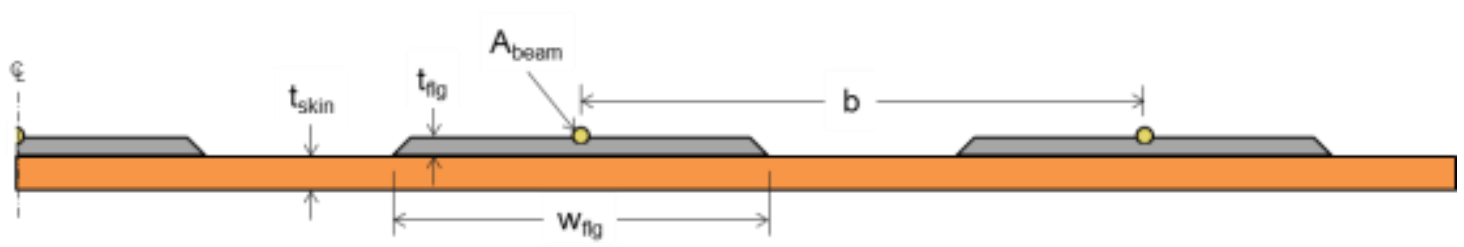

Figure 12. Variable definition of FE analysis configurations.

Panels containing both a skin thickness of 0.2 inches and a stiffener spacing of 12 inches (i.e., Panels 103, 104, $111,112)$ exhibited skin instabilities prior to panel failure. The results from these panels were discounted in subsequent reduction of the FE analysis results.

\section{A. Curvature Effects}

To evaluate the existence of a detrimental effect of curvature on residual strength, FE analysis of the 12 nonbuckling configurations presented in Table 2 was performed for flat panels and panels having an outer radius similar to that of the Boeing 787 aircraft ( $R=117$ inches). A direct comparison of the flat and curved panel $\mathrm{FE}$ results is presented in Figure 13. The effect of a radius of curvature of 117 inches on the residual strength in compression of the 12 configurations evaluated ranges from a $1 \%$ reduction to a $5 \%$ increase. 


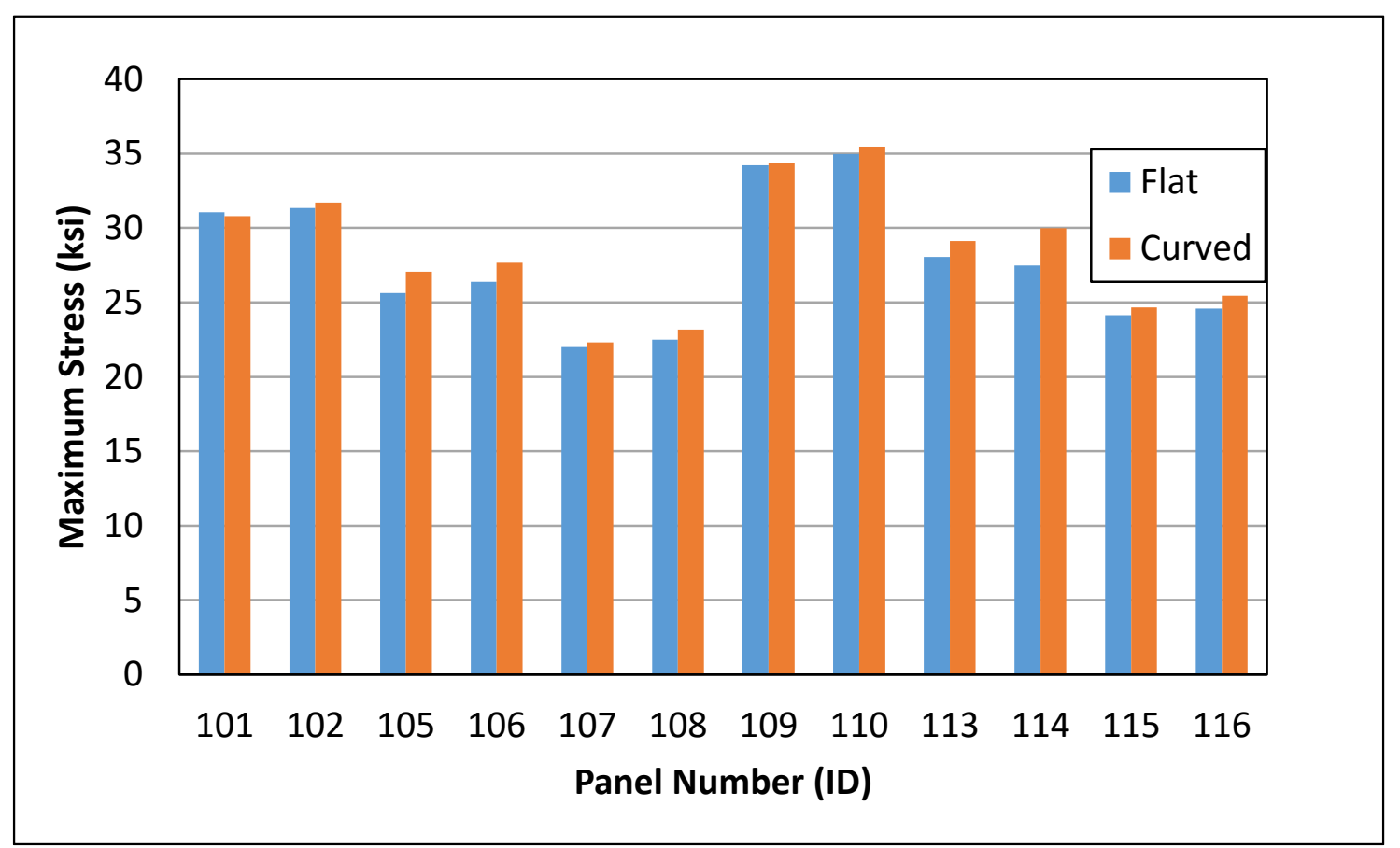

Figure 13. FE results for flat and curved analysis configurations.

\section{B. Stiffener Effects}

Compression Y-factor response surfaces were created, based on the functional forms identified in Section III, by calibrating the coefficients in Eqs. (4)-(5) using results from FE analyses of flat panels. The resulting response surface is contained in Eqs. (6), and is compared in Figure 14 to the results of the FE analyses. The calibrated response surface is within 5\% of all FE analysis results.

$$
\begin{gathered}
Y_{\text {sig }}=\left(0.356 \cdot R_{S}+1.0\right) \cdot C \cdot[0.10]^{D} \\
\text { where, } \quad C=\frac{1}{2 \cdot\left[\frac{1}{R_{S}}+1\right]^{-1.2}+1} \\
D=0.75 \cdot\left[\frac{1}{R_{S}}+1\right]^{-5}
\end{gathered}
$$




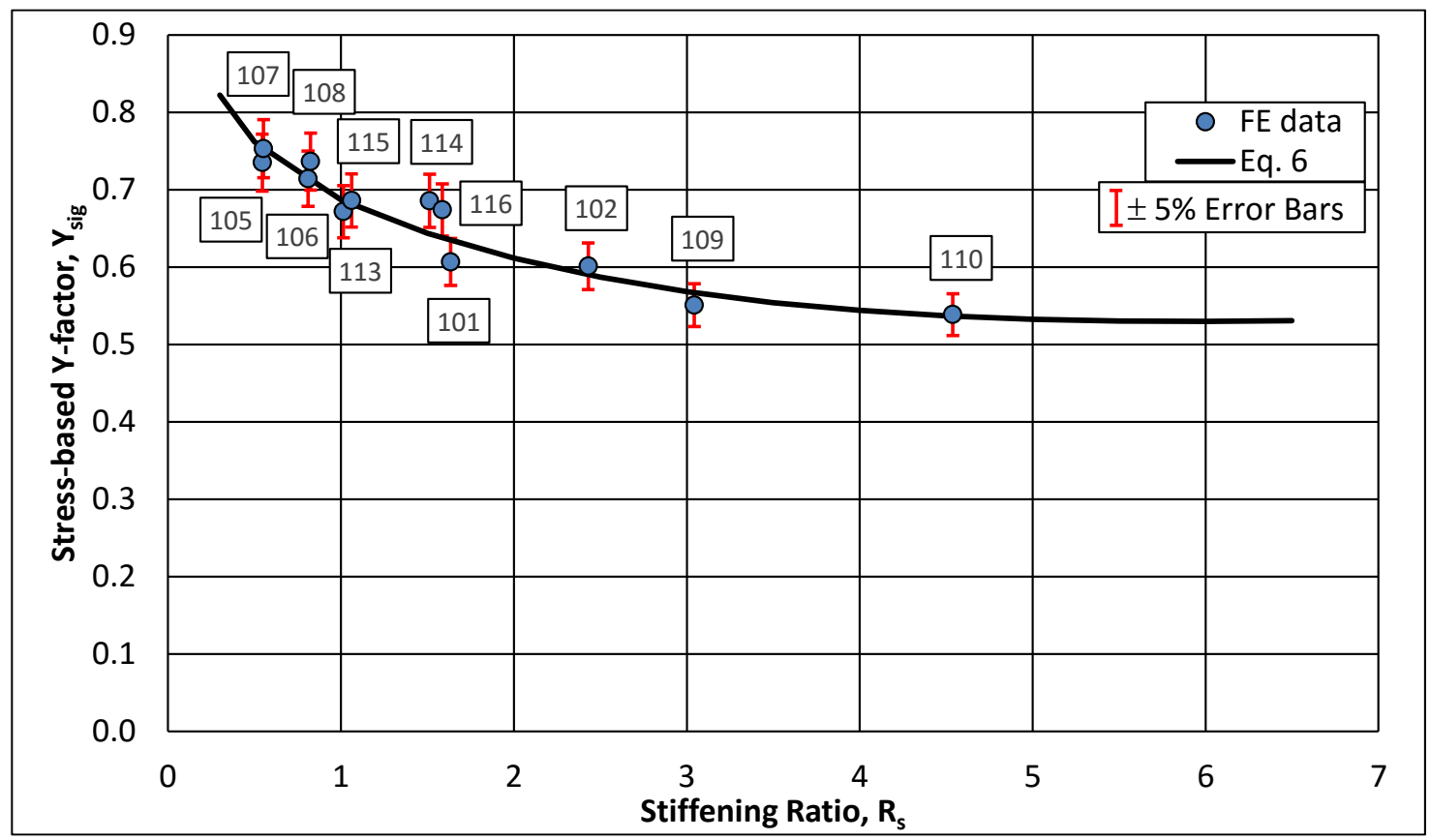

Figure 14. Eq. (6) compression response surface comparison to FE results.

\section{Conclusion}

Results from the current effort suggest two primary conclusions. First, direct comparison of limited FE results for identical flat and curved panels support the expectation that curvature effects are small for the scenario under consideration. Specifically, this was demonstrated for a radius of curvature typical of wide-body commercial aircraft $(\mathrm{R}=117$ in). Secondly, limited FE results also suggest that the functional forms addressing stiffening effects in metallic structure $\left(\right.$ Sanders ${ }^{6}$ and $\mathrm{Poe}^{8}$ ), dependent only on the panel stiffening ratio, provide a reasonable framework for predicting these effects in composite stiffened panels.

This initial development work is applicable for uniaxial loading and panels exhibiting self-similar damage growth from a sharp notch severing a central stiffener. The supporting FE analyses were performed with compression loading, but the conceptual approach is anticipated to also be applicable to tension loading.

Additional work is necessary for these approaches to reach a level of maturity compatible with industry usage for preliminary design. A wider range of panel configurations should be addressed (via FEA) to ensure the applicability of the findings to a large design space, and to identify any additional important variables affecting the Y-factors. Smaller radii of curvature should be addressed. The approach should also be extended to develop a response surface addressing uniaxial tension loading. Finally, the resulting response surfaces should be validated with limited testing.

\section{References}

${ }^{1}$ Anderson, M. J. and Whitcomb, P. J., RSM Simplified: Optimizing Processes Using Response Surface Methods for Design of Experiments, Productivity Press, New York, 2005.

${ }^{2}$ ABAQUS ${ }^{\circledR}$, Software Package, Ver. 6.14-1, Dassault Systèmes Simulia Corporation, Waltham, MA, 2014.

${ }^{3}$ Sanders, J. L., "Circumferential Through-Cracks in Cylindrical Shells Under Tension," Journal of Applied Mechanics, Vol. 49, No. 1, 1982, pp. 103-107.

${ }^{4}$ Forman, R. G., Hickman, J. C. and Shivakumar, J.L., "Stress Intensity Factor for Circumferential Through Cracks in Hollow Cylinders subjected to Combined Tension and Bending Loads," Engineering Fracture Mechanics, Vol. 21, No. 3, 1985, pp. 563571.

${ }^{5}$ Swift, T., "The Impact of Fracture Mechanics on Structural Design," WESTEC Engineering Conference, 1974.

${ }^{6}$ Sanders, J. L., "Effect of a Stringer on the Stress Concentration due to a Crack in a Thin Sheet," NACA-TN-4207, 1958.

${ }^{7}$ Greif, R. and Sanders, J. L., "The Effect of a Stringer on the Stress in a Cracked Sheet," Journal of Applied Mechanics, Vol. 32, No. 1, 1965, pp. 59-66.

${ }^{8}$ Poe, C. C., Jr., "Stress Intensity Factor for a Cracked Sheet with Riveted and Uniformly Spaced Stringers," NASA-TR-R$358,1971$.

${ }^{9}$ Nichols, L. F., Jefferson, A., and Martin, C. I. P., “Integral Structures,” AGARD-AG-257, 1980, pp. 5-1-5-21. 